\title{
Identification of Hydraulic Conductivity in Aquifer for Coupled FEM and Adaptive Genetic Algorithm
}

\author{
Xianghui Deng, ${ }^{1,2}$ Haibo Fang, ${ }^{2}$ Jianxun Chen, ${ }^{1}$ and Junshu Kou ${ }^{2}$ \\ ${ }^{1}$ School of Highway, Chang'an University, Xi'an, Shaanxi 710064, China \\ ${ }^{2}$ School of Civil and Architecture Engineering, Xian Technological University, Xian, Shaanxi 710032, China \\ Correspondence should be addressed to Xianghui Deng; dh_gl@163.com
}

Received 28 December 2014; Revised 9 June 2015; Accepted 24 June 2015

Academic Editor: Franklin A. Mendivil

Copyright (c) 2015 Xianghui Deng et al. This is an open access article distributed under the Creative Commons Attribution License, which permits unrestricted use, distribution, and reproduction in any medium, provided the original work is properly cited.

\begin{abstract}
The hydraulic conductivity of a natural rock mass was difficult to determine because of the complex structure and the significant influence of uncertain factors. In this paper, hydraulic conductivity was adopted to conduct an inversion analysis according to the measurement of head materials by combining the finite element method with the adaptive genetic algorithm. The results showed that the maximum relative error of the measuring and computation groundwater levels at the measuring points was $5.3 \%$, and the average head error was $1.41 \%$; the effective hydraulic conductivity of intensively weathered layer, moderately weathered layer, and fresh bedrock layer in riverbed formation tended to decline gradually; the effective permeability coefficient in direction $Y$ was the minimum in the same aquifer. Therefore, the established hydraulic conductivity inversion analysis method was effective.
\end{abstract}

\section{Introduction}

The seepage characteristics of a rock mass closely were related to the permeability of fissure structural planes. In process of inversion analysis, the seepage parameter was a wide value range mass or the calculation result exhibited discreteness. The main reasons were the complex composition of the structural plane, with the calculation result easily depending on the initial value of the parameter and falling into the local optimum. Thus, it was difficult to determine the value of seepage parameters with the inversion methods. In the 1960 s, a field survey method was adopted to determine seepage parameters by snow. Although the method was simple and easy to implement, the required cost was high, and the measuring result had poor representativeness [1]. In a later study, Kitamura, Chavent, Yeh, and others analysed the hydraulic conductivity inversely through an analytical or semianalytical solution [2-4]. Nevertheless, given that the assumed conditions always differed from actual conditions, the result was difficult to apply. After the 1980s, with a thorough study of the seepage model of rock mass, a back analysis method had been conducted to identify the seepage parameters of the discrete fracture medium $[5,6]$. In the midand late 1990s, the inversion theory of seepage coefficients was developed rapidly [7-9]. In particular, with the rapid development of an optimal algorithm, the inversion method of seepage coefficients had significantly developed greatly and acquired numerous achievements [10-12]. Although the progress had been made on the seepage coefficient inversion analysis of rock mass, it was still difficult to identify that the seepage parameters of rock mass rigorously, accurately, rapidly, and economically had been proposed.

In this study, geological survey, water pressure test, and groundwater level were tested in the field, and other analyses were conducted in relation to hydraulic engineering. These field tests were conducted based on the combined influences of different actual seepage factors. Given that the observation period was short, problems such as the sudden change in drilling water data and high discreteness of the water pressure test data occurred periodically, thus making the determination of the seepage parameter of rock mass difficult. The finite element method combined with an optimal algorithm 
was adopted to analyze the seepage parameters of different areas in a rock mass inversely through the iteration method according to the measured hydraulic heads.

\section{Basic Principle of the Inversion Method}

2.1. Mathematical Model. The concept of hydraulic conductivity dates back to the middle nineteenth century. According to the current research results, three related concepts (effective hydraulic conductivity, equivalent conductivity, and interpreted conductivity) are defined according to the different conditions and assumptions [13]. During the last 40 years, an enormous amount of work has been devoted to research and identify representative hydraulic conductivity. Actually, hydraulic conductivity $(K)$ is arguably one of the most variable parameters in the Earth sciences. Laboratory measurements of $K$ span more than 12 orders of magnitude. Even in seemingly homogeneous aquifers, measured values of $K$ may range over some orders of magnitude. This realization spurred a large amount of work on the problem of finding the effect of heterogeneity on flow and transport.

Up to now, most theoretical results are related to effective conductivity, and their application to real world scenarios relies on ergodic assumptions. Fortunately, a number of results are available suggesting that conventional hydraulic test interpretations yield (interpreted) hydraulic conductivity values that can be closely linked to equivalent and/or effective hydraulic conductivities. Actually, the hydraulic conductivity is usually generalized as the ensemble averages of flux and head gradient in engineering projects, that is, effective hydraulic conductivities. Effective hydraulic conductivities will be analysed in this paper.

Equivalent continuum medium seepage model was widely applied in many actual engineering projects owing to the simplicity of model. The permeability of rock mass was considered as the effective hydraulic conductivities of a certain area. The three-dimensional seepage control equation was expressed as follows [14]:

$$
\begin{aligned}
& \frac{\partial}{\partial x}\left(K_{x} \frac{\partial H}{\partial x}\right)+\frac{\partial}{\partial y}\left(K_{y} \frac{\partial H}{\partial y}\right)+\frac{\partial}{\partial z}\left(K_{z} \frac{\partial H}{\partial z}\right) \\
& =S_{s} \frac{\partial H}{\partial t}
\end{aligned}
$$

where $S_{s}$ was the unit storage volume; $H$ was the hydraulic head; $K_{x}, K_{y}$, and $K_{z}$ were the hydraulic conductivity of rock mass in three directions. When conducting steady seepage analysis, the right side of the equation was equal to 0 . In this paper, three-dimensional steady seepage analysis was used.

2.2. Objective Function. The effective hydraulic conductivity was analysed as the inversion parameters in this paper. Firstly, the water heads were calculated through three-dimensional finite element numerical analysis. Then, the error of measurement and computation head were calculated on the base of the measured groundwater levels of the natural seepage field. Finally, the effective hydraulic conductivity values were identified through the optimization of the adaptive genetic algorithm when the error was minimised. The objective function was given as follows:

$$
F\left(K_{x}, K_{y}, K_{z}\right)=\sqrt{\sum_{i=1}^{n}\left[\frac{h_{i}-h_{i}^{\prime}}{h_{i}^{\prime}}\right]^{2}},
$$

where $K_{x}, K_{y}$, and $K_{z}$ were the effective hydraulic conductivity to be used for the inversion analysis; $h_{i}$ was the computation head at measuring point $i ; h_{i}^{\prime}$ was the measuring head at measuring point $i$; and $n$ was the total number of measuring points. The relative value of the head was adopted to make the objective function a dimensionless numerical function to avoid other problems during optimisation and to determine whether the algorithm was converged [15].

2.3. Boundary Conditions. According to the established field model and actual engineering practice, the boundary conditions were as follows:

(1) The Class-I boundary referred to the measured groundwater level. The borehole was drilled on the cross section while the groundwater level was measured. The hydraulic heads of the leftmost and rightmost sides defined the Class-I head boundary, such that the hydraulic head was known.

(2) The leftmost and rightmost sides of the model measuring the saturated surface referred to the Class-II (known discharge) boundary. The seepage discharge of these boundary surfaces was zero.

2.4. Adaptive Genetic Algorithms. In traditional genetic algorithm, crossover rate $P_{c}$ and mutation rate $P_{m}$ are the key factors influencing the behavior and performance of genetic algorithm. However, these two factors are predetermined in traditional genetic algorithm, and $P_{c}$ and $P_{m}$ should be determined through repeated tests specific to different optimization problems and tend to be trapped by local optimal solution. To solve the problem effectively, adaptive genetic algorithm in which $P_{c}$ and $P_{m}$ change automatically with the adaptability is presented in this paper; expressions are as follows:

$$
\begin{gathered}
P_{c}= \begin{cases}P_{c 1}-\frac{\left(P_{c 1}-P_{c 2}\right)\left(f^{\prime}-f_{\mathrm{avg}}\right)}{f_{\max }-f_{\mathrm{avg}}} & f^{\prime} \geq f_{\mathrm{avg}} \\
P_{c 1} & f^{\prime}<f_{\mathrm{avg}},\end{cases} \\
P_{m}= \begin{cases}P_{m 1}-\frac{\left(P_{m 1}-P_{m 2}\right)\left(f_{\max }-f\right)}{f_{\max }-f_{\mathrm{avg}}} & f \geq f_{\mathrm{avg}} \\
P_{m 1} & f<f_{\mathrm{avg}},\end{cases}
\end{gathered}
$$

where $f_{\max }$ refers to the maximum individual fitness in each generation; $f_{\text {avg }}$ refers to average fitness of each generation; $f^{\prime}$ refers to the larger one between two crossover individuals; $f$ refers to the fitness of mutant individual. In general, the initial value of $P_{c 1}, P_{c 2}, P_{m 1}$, and $P_{m 2}$ in the expressions above can be $0.9,0.6,0.1$, and 0.001 , respectively.

If the individual fitness in a population tends to be uniform or local optimum, the algorithm is able to increase 
the values of crossover rate and mutation rate automatically, and the optimal solution can be obtained avoiding the algorithm from falling into the local optimum solution. Meanwhile, individual with fitness higher than the average fitness corresponds to lower $P_{c}$ and $P_{m}$, so that the next generation can be protected by the solution. Individual with fitness lower than average corresponds to higher crossover rate and mutation rate; hence the solution can be eliminated. Therefore, the adaptive algorithm constructed is able to guarantee the convergence of genetic algorithm while maintaining the population diversity.

2.5. Inversion Analysis Procedures. Since adaptive genetic algorithm was very effective to solve the multiobjective optimization problem, it was adopted to identify the effective hydraulic conductivity in this paper. The inversion analysis was divided into the following procedures:

(1) Coding: adaptive genetic algorithm was adopted to transform $K_{x}, K_{y}$, and $K_{z}$ into coded strings.

(2) Generation of initial group: $n$ initial groups were generated at random within the preset parameter scope.

(3) Computation of objective function value: the initial solvable group was encoded into the finite element analysis program of seepage and the objective function value was then computed.

(4) Evaluation of fitness: the result of the finite element analysis program for seepage was used to evaluate the individual fitness and to compute the average fitness of groups.

(5) Convergence determination: the judging basis was considered when the difference of the maximum fitted value and the average fitted value of group was less than the preset error, and the maximum evolution generation was considered as the auxiliary judgment.

(6) Genetic evolution operation: optional, cross, and mutation operations were performed, and a new generation of solvable groups was formed according to the operational approach of adaptive genetic algorithm.

(7) When a new solvable group was obtained, Step (3) was repeated until the objective function value satisfies the error precision.

(8) Optimised objective function value and optimised inversion parameters were obtained.

The procedure for the inversion of the hydraulic conductivity was as shown in Figure 1.

\section{Engineering Situation}

A hydropower station was situated in the main stream of the upper reach of Lancang River in the territory of Diqing Tibetan Autonomous Prefecture, Yunnan. Hydropower was mainly used to generate power. The normal groundwater level of the reservoir was $1,906.0 \mathrm{~m}$, the downstream groundwater level was $1,814.86 \mathrm{~m}$, and the normal storage capacity was $265,000,000 \mathrm{~m}^{3}$. The dam area was a cross valley with an asymmetric "V" shape. The natural grade of the left bank slope ranged from $40^{\circ}$ to $50^{\circ}$. The rock mass of bank slope was not completely covered by the weathered layer but was partially covered by the quaternary waste slope gravelly soil with a thickness of approximately $7 \mathrm{~m}$. The natural grade of the right bank below an altitude of $1,910 \mathrm{~m}$ ranges from $60^{\circ}$ to $80^{\circ}$, whereas that above an altitude of $1,910 \mathrm{~m}$ ranged from $40^{\circ}$ to $45^{\circ}$. The strata distributed in the dam area were mainly foliated sandy slate, argillaceous slate, and a spot of tuff. The groundwater under the dam area was divided into fissure water and pore phreatic water according to the mode of occurrence and occurrence medium. Fissure water occurred among rock fissures, whereas pore phreatic water occurred in the quaternary unconsolidated formation. Groundwater was mainly supplemented by atmospheric precipitation as well as melted mountain ice and snow. Such groundwater discharges into Lancang River. According to an adit exploration in the dam area, the groundwater in the rock mass of both banks was deeply buried underground. The hydraulic gradient of the left groundwater was approximately 0.266 , whereas that of the right groundwater was approximately 0.568 .

The riverbed covering layer was alluvial sand and gravel cobble, with a thickness of $19.8 \mathrm{~m}$ to $25 \mathrm{~m}$. The rock roof altitude was approximately $1,782 \mathrm{~m}$. The rock of the riverbed was mainly sandy and argillaceous slate. The average depth of the strongly weathered rock on the riverbed ranges from $5 \mathrm{~m}$ to $6 \mathrm{~m}$. The vertical depth (below the rock plane) of the weakly weathered belt ranged from $6 \mathrm{~m}$ to $15 \mathrm{~m}$, and the fresh rock was distributed at approximately $15 \mathrm{~m}$ to $46 \mathrm{~m}$ below the surface. The hydrogeological section map in the study area was shown in Figure 2.

\section{Back Analyses of the Hydraulic Conductivity of Different Strata}

4.1. Variation Range of Initial Hydraulic Conductivity. According to the geological plane of the dam area, the profiles of cross sections, and the geological material of the project, a natural seepage field model of the dam area was established. In the model, the permeability of the different strata significantly differed from top to bottom. The dam foundation area was divided into four layers: the alluvial, strongly weathered, weakly weathered, and fresh rock layers, from top to bottom. The dam shoulders on the left and right banks were considered to have varying permeability. The natural seepage field model of the dam area was shown in Figure 3.

The equivalent continuous medium seepage model was adopted on the analysis, and the effective hydraulic conductivity values were taken as the parameters for inversion. Considering the number of multiple layers, the degree of parameter inversion was reduced to lessen the computational load. The effective hydraulic conductivity of the riverbed alluvial layer could be determined based on engineering experience. The riverbed alluvial layer was formed through the alleviation of soil, gravel, sand, and so forth, and its 


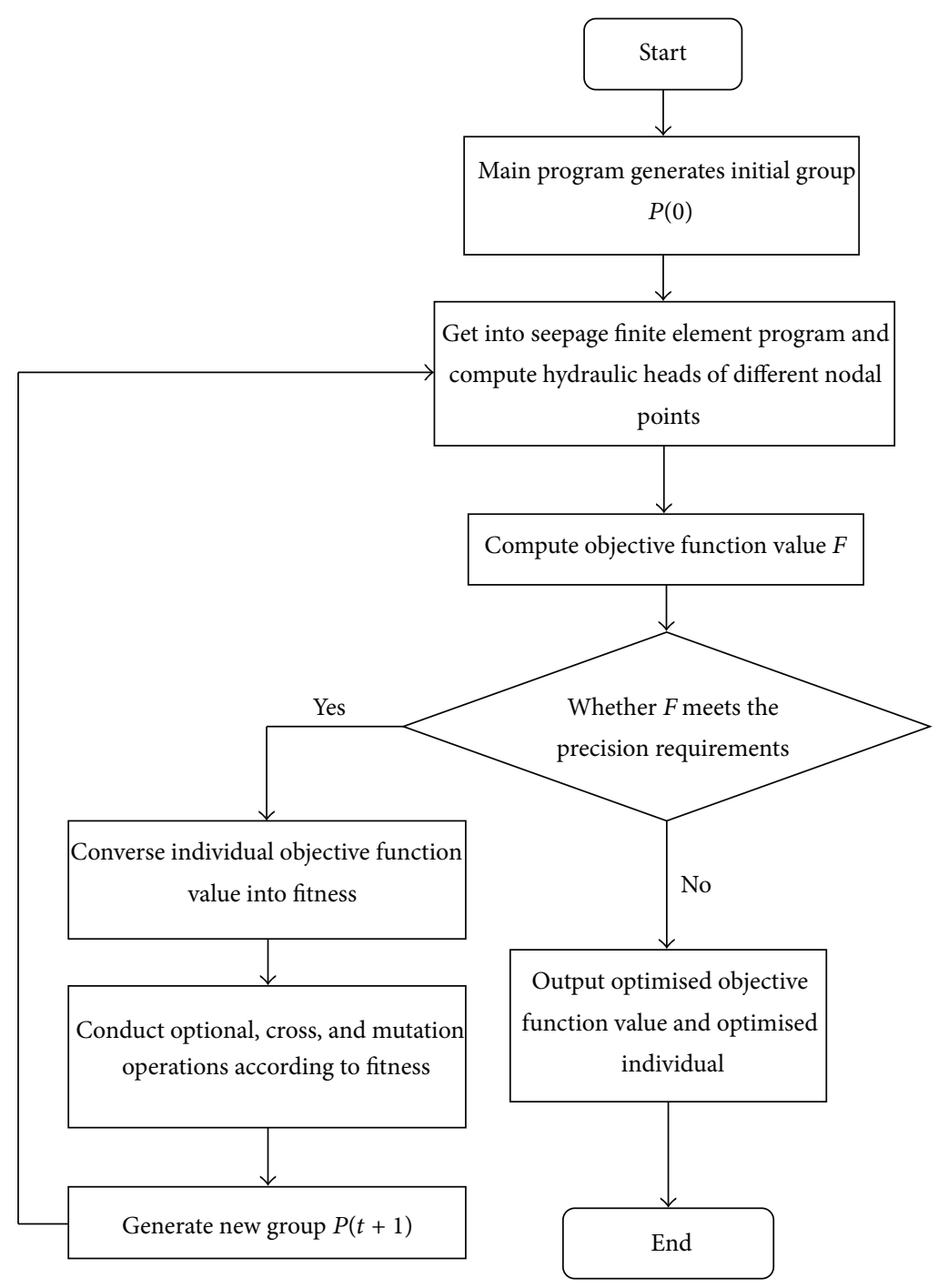

Figure 1: Program flow chart of the inversion analysis of the hydraulic conductivity.

TABLE 1: Variation ranges of the effective hydraulic conductivity of different strata.

\begin{tabular}{|c|c|c|c|c|c|c|}
\hline \multirow{2}{*}{ Stratum } & \multicolumn{2}{|c|}{ Range of $K_{x}(\mathrm{~m} / \mathrm{s})$} & \multicolumn{2}{|c|}{ Range of $K_{y}(\mathrm{~m} / \mathrm{s})$} & \multicolumn{2}{|c|}{ Range of $K_{z}(\mathrm{~m} / \mathrm{s})$} \\
\hline & Upper limit & Lower limit & Upper limit & Lower limit & Upper limit & Lower limit \\
\hline Strongly weathered layer & $1 \times 10^{-3}$ & $1 \times 10^{-7}$ & $1 \times 10^{-3}$ & $1 \times 10^{-7}$ & $1 \times 10^{-3}$ & $1 \times 10^{-7}$ \\
\hline Weakly weathered layer & $1 \times 10^{-3}$ & $1 \times 10^{-7}$ & $1 \times 10^{-3}$ & $1 \times 10^{-7}$ & $1 \times 10^{-3}$ & $1 \times 10^{-7}$ \\
\hline Fresh rock layer & $1 \times 10^{-4}$ & $1 \times 10^{-8}$ & $1 \times 10^{-4}$ & $1 \times 10^{-8}$ & $1 \times 10^{-4}$ & $1 \times 10^{-8}$ \\
\hline Left bank rock & $1 \times 10^{-4}$ & $1 \times 10^{-8}$ & $1 \times 10^{-4}$ & $1 \times 10^{-8}$ & $1 \times 10^{-4}$ & $1 \times 10^{-8}$ \\
\hline Right bank rock & $1 \times 10^{-4}$ & $1 \times 10^{-8}$ & $1 \times 10^{-4}$ & $1 \times 10^{-8}$ & $1 \times 10^{-4}$ & $1 \times 10^{-8}$ \\
\hline
\end{tabular}

hydraulic conductivity was $1 \times 10^{-3} \mathrm{~m} / \mathrm{s}$ according to relative engineering experience. The effective hydraulic conductivity values of the strongly and weakly weathered layers of the riverbed as well as of the left and right bank rocks were analysed in this paper. According to a similar project, the ranges of the initial value of the parameters were given in Table 1.
4.2. Finite Element Model. The dam axis was $y$-axis, whereas the right bank direction was positive. $x$-direction was perpendicular to $y$-direction, and the water flow direction was positive. The vertical direction was $z$-axis, whereas the positive direction was vertically upward (Figure 4).

The origin $O$ of the model was situated at $z$-coordinate, which was $1,600 \mathrm{~m}$ below the intersection of $x$-and $y$-axes. 


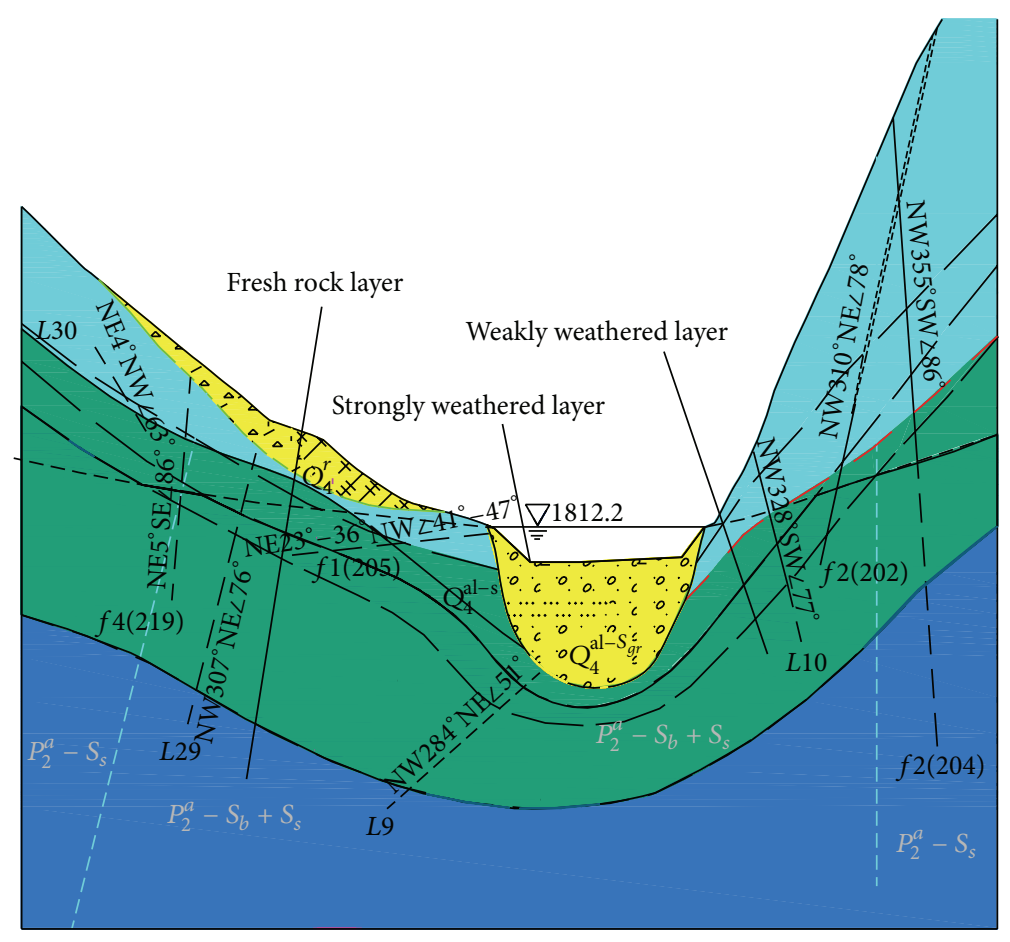

FIgURE 2: Hydrogeological section map in the study area.

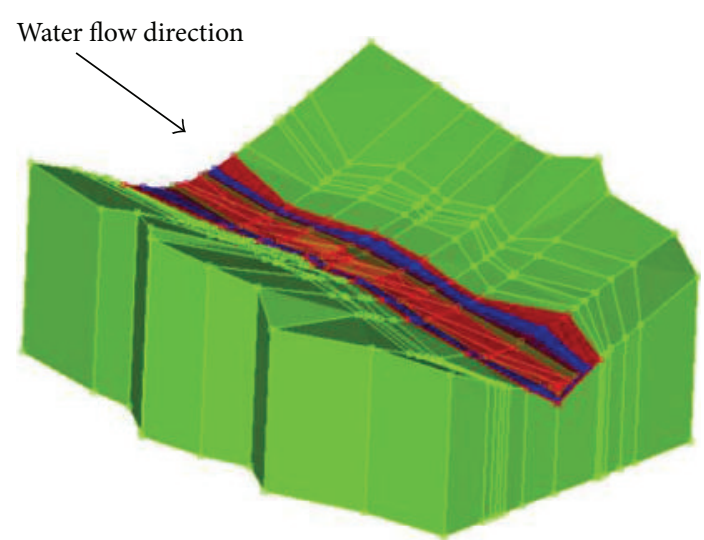

FIgURE 3: Natural seepage field model of the dam area.

The model measures $910 \mathrm{~m} \times 820 \mathrm{~m} \times 400 \mathrm{~m}$. Based on the finite element subdivision, the model comprises 32,486 nodes and 34,320 hexahedron elements (Figure 4).

4.3. Computation Results and Analysis. The optimised inversion parameter combination corresponding to the minimum error of the measuring and computation heads was obtained through optimal computation. The measuring and computation heads at all measuring points were calculated for comparison (Table 2). In Table 2, the difference $(186.5 \mathrm{~m})$ between the maximum head $(1,997 \mathrm{~m})$ and the minimum head $(1,810.5 \mathrm{~m})$ was selected as the basis for the comparison between the measured and computed groundwater levels.

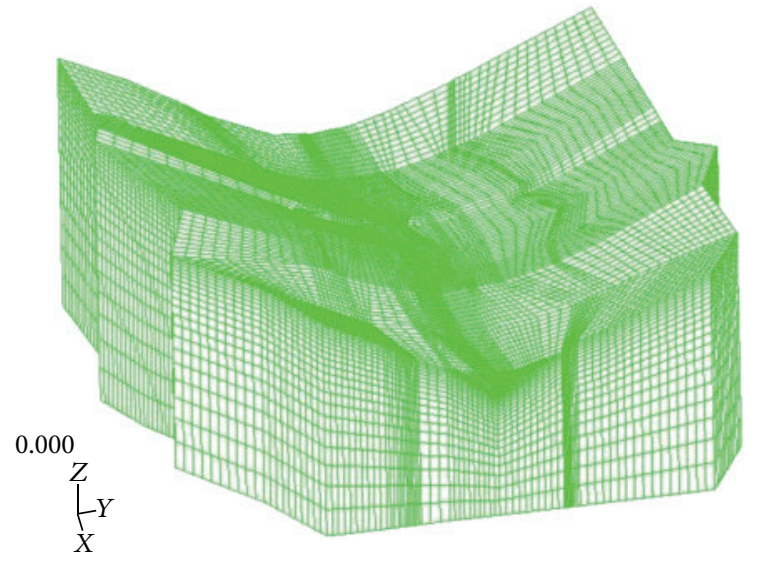

FIGURE 4: Finite element model of the computation zone.

The relative error refers to the ratio of the absolute error of the computation and measuring heads to the base.

Table 2 showed that the error of the measuring and computation heads of different measuring points was relatively small, and the average error of the measuring points in the dam area was only $1.41 \%$. The computed groundwater level of the boreholes was higher than the measured value when the error was at the minimum value. The maximum error point was at ZK213, with a relative error of $5.3 \%$. These results indicated that the inversion analysis model could reflect the permeability characteristic of the model area equivalently and macroscopically. Nevertheless, the position of the computation phreatic line remained relatively high. 
TABLE 2: Error of the hydraulic heads of the measuring and computation.

\begin{tabular}{|c|c|c|c|c|}
\hline Borehole number & Measuring level (m) & Computation level (m) & Absolute error $(\mathrm{m})$ & Relative error (\%) \\
\hline ZK225 & 1812.20 & 1812.40 & 0.25 & 0.10 \\
\hline ZK226 & 1812.20 & 1812.60 & 0.40 & 0.20 \\
\hline ZK227 & 1812.20 & 1812.00 & -0.20 & 0.10 \\
\hline ZK228 & 1812.20 & 1812.70 & 0.50 & 0.27 \\
\hline ZK214 & 1812.30 & 1813.10 & 0.80 & 0.20 \\
\hline ZK237(1) & 1813.00 & 1812.50 & -0.50 & 0.27 \\
\hline ZK237(2) & 1813.00 & 1812.40 & -0.60 & 0.32 \\
\hline ZK205 & 1814.00 & 1812.60 & -1.40 & 0.76 \\
\hline ZK216(4) & 1814.39 & 1812.80 & -1.59 & 0.86 \\
\hline ZK201 & 1815.11 & 1820.40 & 5.29 & 2.86 \\
\hline ZK273 & 1819.00 & 1822.80 & 3.80 & 2.05 \\
\hline ZK234 & 1821.00 & 1824.40 & 3.40 & 1.84 \\
\hline ZK213 & 1822.00 & 1831.80 & 9.80 & 5.30 \\
\hline ZK221 & 1825.04 & 1829.90 & 4.86 & 2.63 \\
\hline ZK207 & 1830.00 & 1829.70 & -0.30 & 0.16 \\
\hline ZK239(2) & 1834.00 & 1836.70 & 2.70 & 1.46 \\
\hline ZK216(10) & 1834.55 & 1841.50 & 6.95 & 3.76 \\
\hline ZK239(1) & 1834.58 & 1835.80 & 1.22 & 0.66 \\
\hline ZK218 & 1837.97 & 1837.20 & -0.77 & 0.42 \\
\hline ZK204 & 1851.00 & 1855.60 & 4.60 & 2.49 \\
\hline ZK250 & 1884.63 & 1889.40 & 4.77 & 2.58 \\
\hline ZK206 & 1887.00 & 1884.00 & -3.00 & 1.62 \\
\hline
\end{tabular}

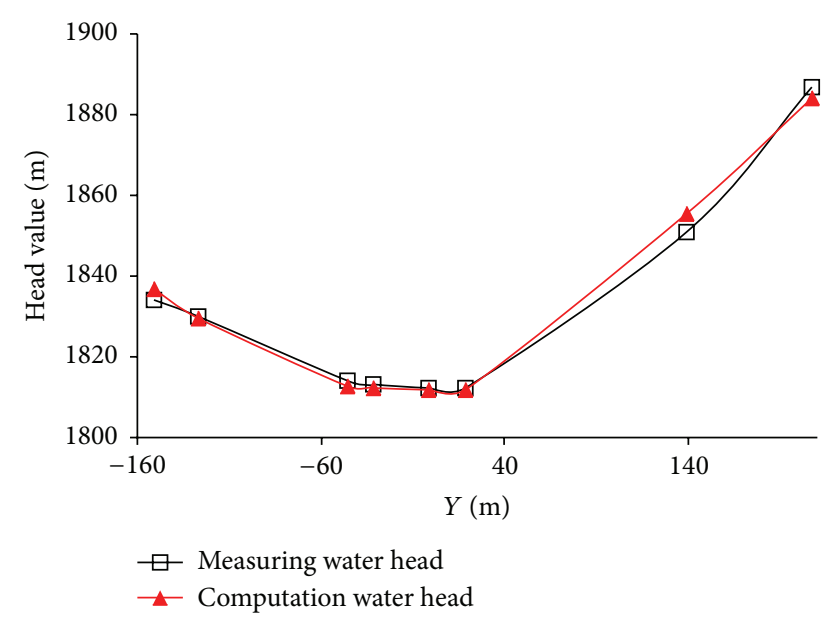

Figure 5: Measuring and computation heads of the axis cross section.

For the validation of computation accuracy, visual graphic comparisons were established for the axis cross section, where intensive measuring points were located. The cross section on the upstream was $30 \mathrm{~m}$ away from the dam (Figures 5 and 6 as well as Tables 3 and 4).

Table 3 and Figure 5 showed that the error of the computation and measuring head values of the measuring points of the axis cross section was relatively small. The minimum error was $0.2 \mathrm{~m}$ at $\mathrm{ZK} 227$, with a relative error of $0.1 \%$. The maximum head error was at ZK204, with an error value of $4.6 \mathrm{~m}$ and relative error of $2.49 \%$. The average error of

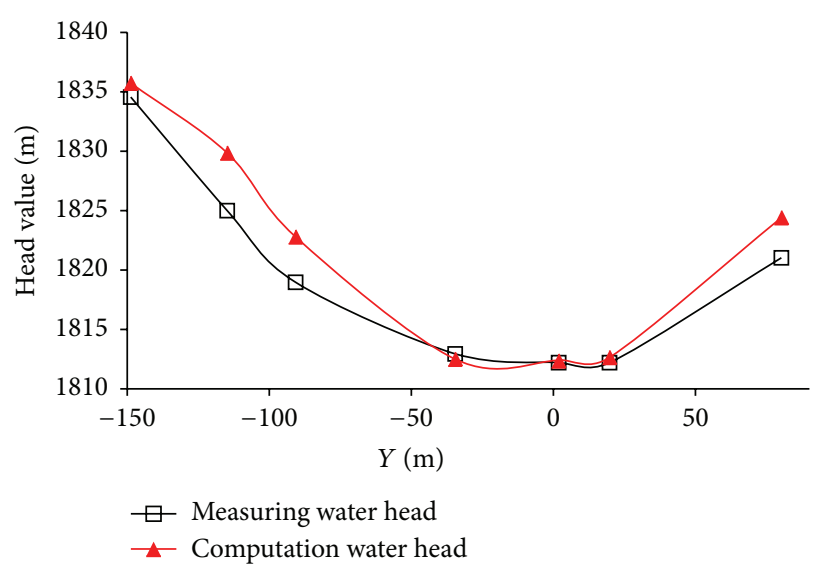

FIGURE 6: Measuring and computation heads on the cross section of the upstream (30 $\mathrm{m}$ away from the dam).

the eight measuring points on the axis cross section was only $0.90 \%$, and the inversion analysis error was relatively small.

Table 4 and Figure 6 showed that the error of the computation and measuring head values at the measuring points on the cross section of the upstream $30 \mathrm{~m}$ away from the dam was relatively small. The minimum error value was $0.25 \mathrm{~m}$ at ZK225, with a relative error of $0.1 \%$. The maximum error value was $4.86 \mathrm{~m}$ at ZK221, with a relative error of $2.63 \%$. The average error of the seven measuring points on the cross section of the upstream $30 \mathrm{~m}$ away from the dam was only $1.11 \%$, and the inversion analysis error was relatively 
TABLE 3: Fitting error of the groundwater levels of different boreholes of the axis cross section.

\begin{tabular}{|c|c|c|c|c|c|c|}
\hline Borehole number & $X(\mathrm{~m})$ & $Y(\mathrm{~m})$ & $\begin{array}{c}\text { Measuring } \\
\text { groundwater level } \\
(\mathrm{m})\end{array}$ & $\begin{array}{c}\text { Computation } \\
\text { groundwater level } \\
(\mathrm{m})\end{array}$ & $\begin{array}{l}\text { Absolute error } \\
\qquad(\mathrm{m})\end{array}$ & $\begin{array}{c}\text { Relative } \\
\text { error } \\
(\%)\end{array}$ \\
\hline ZK227 & 0 & -2 & 1812.20 & 1812.00 & -0.20 & 0.10 \\
\hline ZK228 & 0 & 18 & 1812.20 & 1812.70 & 0.50 & 0.27 \\
\hline ZK237(2) & 0 & -32 & 1813.00 & 1812.40 & -0.60 & 0.32 \\
\hline ZK205 & 0 & -46 & 1814.00 & 1812.60 & -1.40 & 0.76 \\
\hline ZK207 & 0 & -127 & 1830.00 & 1829.70 & -0.30 & 0.16 \\
\hline ZK239(2) & 0 & -151 & 1834.00 & 1836.70 & 2.70 & 1.46 \\
\hline ZK204 & 0 & 139 & 1851.00 & 1855.60 & 4.60 & 2.49 \\
\hline ZK206 & 0 & 207 & 1887.00 & 1884.00 & -3.00 & 1.62 \\
\hline
\end{tabular}

TABLE 4: Error of the groundwater levels of different boreholes on the cross section of the upstream ( $30 \mathrm{~m}$ away from the dam).

\begin{tabular}{|c|c|c|c|c|c|c|}
\hline Borehole number & $X(\mathrm{~m})$ & $Y(\mathrm{~m})$ & $\begin{array}{c}\text { Measuring } \\
\text { groundwater level } \\
(\mathrm{m})\end{array}$ & $\begin{array}{c}\text { Computation } \\
\text { groundwater level } \\
(\mathrm{m})\end{array}$ & $\begin{array}{l}\text { Absolute } \\
\text { error }(m)\end{array}$ & $\begin{array}{l}\text { Relative } \\
\text { error (\%) }\end{array}$ \\
\hline ZK225 & -30 & 1.9 & 1812.20 & 1812.40 & 0.25 & 0.10 \\
\hline ZK226 & -30 & 19.9 & 1812.20 & 1812.60 & 0.40 & 0.20 \\
\hline ZK237(1) & -30 & -34.3 & 1813.00 & 1812.50 & -0.50 & 0.27 \\
\hline ZK273 & -30 & -90.6 & 1819.00 & 1822.80 & 3.80 & 2.05 \\
\hline ZK234 & -30 & 80.2 & 1821.00 & 1824.40 & 3.40 & 1.84 \\
\hline ZK221 & -30 & -114.7 & 1825.04 & 1829.90 & 4.86 & 2.63 \\
\hline ZK239(1) & -30 & -148.9 & 1834.58 & 1835.80 & 1.22 & 0.66 \\
\hline
\end{tabular}

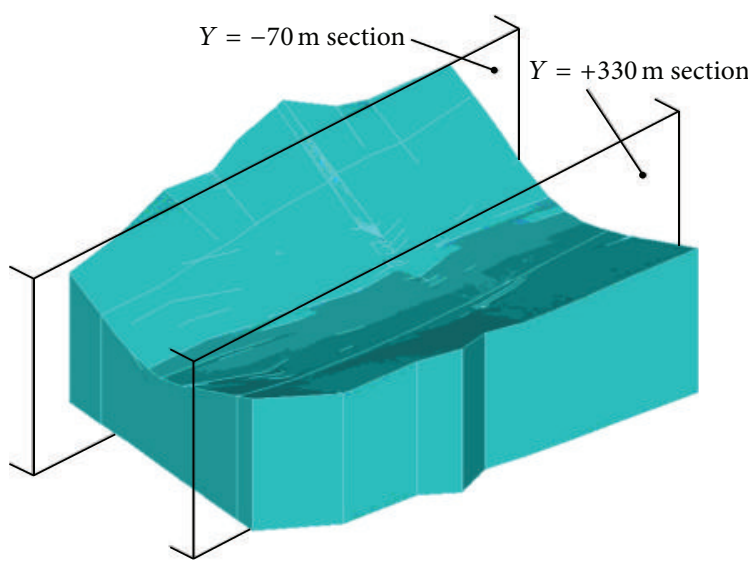

FIGURE 7: Location of the axis cross section.

small. The measuring and computation head error charts of the two cross sections indicated that the farther from the river channel the left or right bank was, the higher the error obtained.

The seepage field within the computation area could be obtained when the objective function was minimised. The seepage field of the axis cross section $(x=0$ section), the cross section of the downstream $205 \mathrm{~m}$ away from the dam $(x=205$ section), the $0 \mathrm{~m}$ to $70 \mathrm{~m}$ longitudinal section ( $y=$ -70 section) of the left and right banks, and the $0+330 \mathrm{~m}$ longitudinal section ( $y=330$ section) were used to illustrate

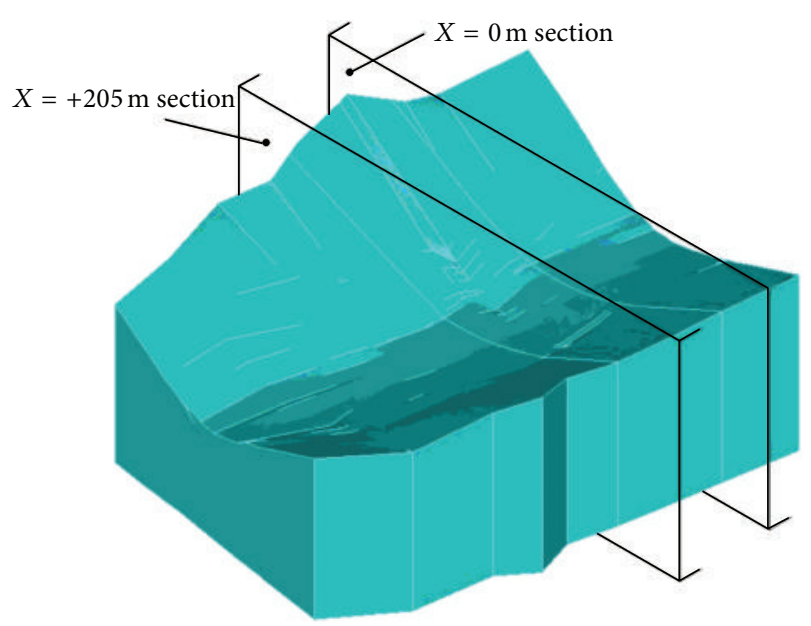

FIGURE 8: Location of the axis cross section.

the condition of the seepage field (see Figures 7 and 8 for the location diagram and Figures 9-12 for the different positions of the seepage field).

The optimised effective hydraulic conductivity combinations of strata were obtained when the errors of the measuring and computation heads were minimized (Table 5).

The inversion analysis result showed the following. (1) The effective hydraulic conductivity values of the strongly weathered, weakly weathered, and fresh rock layers in the riverbed stratum gradually became small and increasingly 


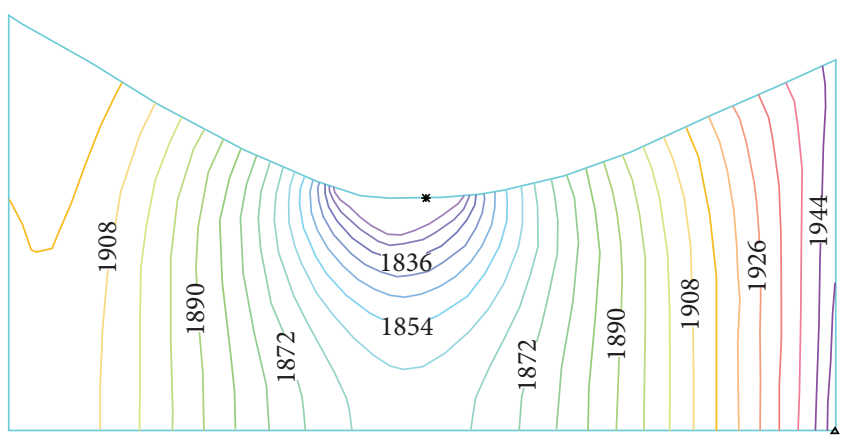

FIGURE 9: Isoline of the hydraulic head of the axis cross section (m).

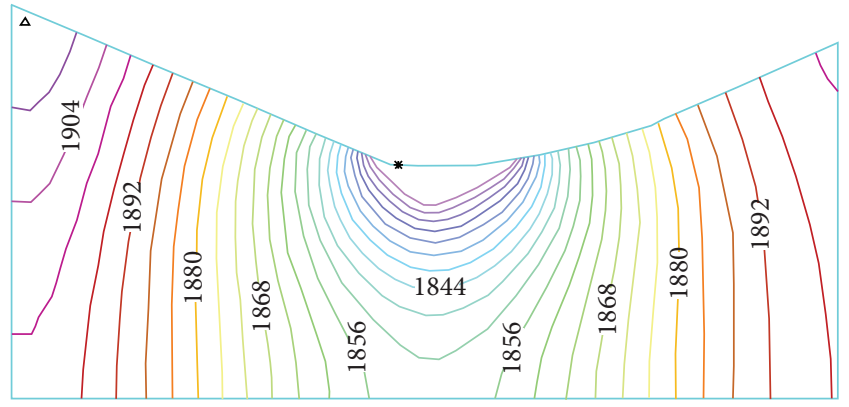

Figure 10: Isoline of the hydraulic head of the upstream at $+205 \mathrm{~m}$ cross section $(\mathrm{m})$.

TABLE 5: Optional result of the effective hydraulic conductivity.

\begin{tabular}{lccc}
\hline Partition & $\begin{array}{c}\text { Hydraulic } \\
\text { conductivity } \\
K_{x} \\
(\mathrm{~m} / \mathrm{s})\end{array}$ & $\begin{array}{c}\text { Hydraulic } \\
\text { conductivity } \\
K_{y} \\
(\mathrm{~m} / \mathrm{s})\end{array}$ & $\begin{array}{c}\text { Hydraulic } \\
\text { conductivity } \\
K_{z} \\
(\mathrm{~m} / \mathrm{s})\end{array}$ \\
\hline $\begin{array}{l}\text { Strongly weathered } \\
\text { layer }\end{array}$ & $4.0 \times 10^{-4}$ & $6.0 \times 10^{-5}$ & $7.0 \times 10^{-4}$ \\
$\begin{array}{l}\text { Weakly weathered } \\
\text { layer }\end{array}$ & $8.0 \times 10^{-6}$ & $1.0 \times 10^{-6}$ & $7.0 \times 10^{-5}$ \\
$\begin{array}{l}\text { Fresh rock layer } \\
\text { Left bank rock }\end{array}$ & $3.0 \times 10^{-7}$ & $1.0 \times 10^{-8}$ & $5.0 \times 10^{-7}$ \\
Right bank rock & $4.0 \times 10^{-7}$ & $1.0 \times 10^{-7}$ & $6.0 \times 10^{-7}$ \\
\hline
\end{tabular}

weak. In the same stratum, $y$-direction effective hydraulic conductivity value was minimised. (2) The effective hydraulic conductivity values of the right bank rock were less than that of the left bank rock, which indicates that the overall integrity of the former was better than that of the latter. This finding was associated with the fact that the hydraulic gradient of the right bank was higher than that of the left bank.

\section{Conclusion}

(1) To overcome the limitation of genetic algorithm, adaptive genetic algorithm was put forward. Combining with finite element method, effective hydraulic

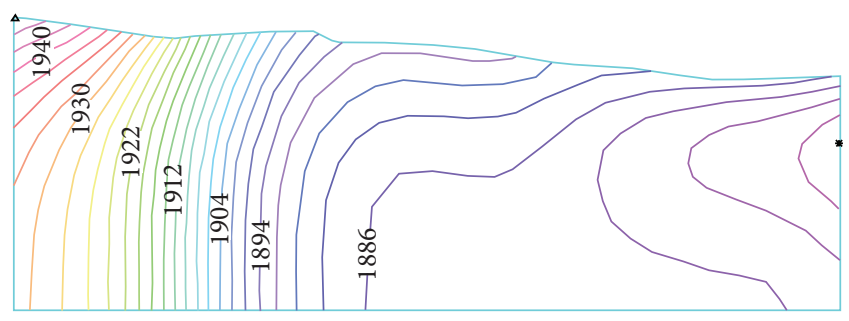

FIgURE 11: Isoline of the hydraulic head of $0-070 \mathrm{~m}$ longitudinal section $(\mathrm{m})$.

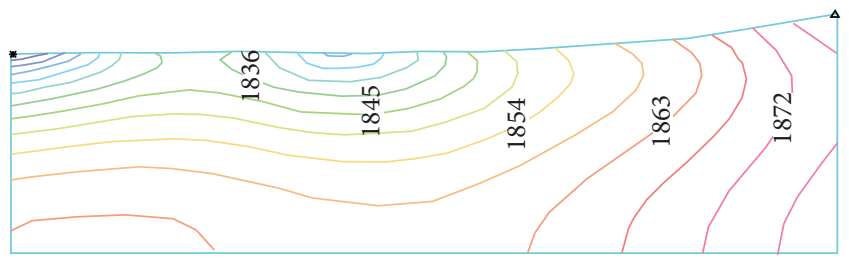

FIGURE 12: Isoline of the hydraulic head of $0+330 \mathrm{~m}$ longitudinal section $(\mathrm{m})$.

conductivity of different aquifers in natural dam foundation was identified. This algorithm overcame the limitations of the traditional optimisation algorithms, in which the inversion result significantly depended on the initial value of $P_{c}$ and $P_{m}$ and fell into the local optimum when the inversion analysis was performed.

(2) According to the inversion analysis result of this study, the maximum relative error of the measuring and computation groundwater levels at the measuring points was $5.3 \%$, and the average head error was $1.41 \%$. The results showed that the established hydraulic conductivity inversion analysis method was effective. Meanwhile, the inversion results showed the effective hydraulic conductivity of intensively weathered layer, moderately weathered layer, and fresh bedrock layer in riverbed formation tended to decline gradually, which reflected that the permeability of aquifer became weaker and weaker, and in the same aquifer, the effective permeability coefficient in direction $Y$ was the minimum.

(3) The result showed that effective hydraulic conductivity of right bank was smaller than that of left bank, which indicated that the rock on left bank was more complete than those on left bank in whole, which coincided well with the condition that the average hydraulic gradient of right bank was larger than that of left bank.

\section{Conflict of Interests}

The authors declare that there is no conflict of interests regarding the publication of this paper. 


\section{Acknowledgments}

This research was financially supported by the National Program on Key Basic Research Project of China (973 Program no. 2013CB036003), National Natural Science Foundation of China (NSFC Grant no. 50579092 sponsored), and the Scientific Research Foundation (2010JK599) by the Education Department of Shaanxi Province.

\section{References}

[1] D. T. Snow, "Rock fracture spacings, openings, and porosities," Journal of the Soil Mechanics and Foundations Division, vol. 94, no. 1, pp. 73-92, 1968.

[2] S. Kitamura and S. Nakagiri, "Identifiability of spatially-varying and constant parameters in distributed systems of parabolic type," The SIAM Journal on Control and Optimization, vol. 15, no. 5, pp. 785-802, 1977.

[3] G. Chavent, "Identification of distributed parameter system: about the output least square method, its implementation and identification," in Identification and System Parameter Estimation, R. Isermann, Ed., vol. 1, pp. 85-97, Pergamon Press, New York, NY, USA, 1979.

[4] W. W.-G. Yeh and N.-Z. Sun, "An extended identifiability in aquifer parameter identification and optimal pumping test design," Water Resources Research, vol. 20, no. 12, pp. 1837-1847, 1984.

[5] Y. W. Tsang and C. F. Tsang, "Channel model of flow through fractured media," Water Resources Research, vol. 23, no. 3, pp. 467-479, 1987.

[6] Y. M. Zhu, L. J. Zhang, and Y. Wu, "Back analysis of coefficient tensor of permeability for fractured rock mass," Chinese Journal of Rock Mechanics and Engineering, vol. 16, no. 1, pp. 461-470, 1997.

[7] M. Oda, "An equivalent model for coupled stress and fluid flow analysis in jointed rock masses," Water Resources Research, vol. 22, no. 13, pp. 1845-1856, 1986.

[8] B. F. Zhu, "A new method for the back analysis of seepage problem," Journal of Hydraulic Engineering, no. 9, pp. 42-46, 1994.

[9] M. Bai, F. Meng, D. Elsworth, Y. Abousleiman, and J.-C. Roegiers, "Numerical modelling of coupled flow and deformation in fractured rock specimens," International Journal for Numerical and Analytical Methods in Geomechanics, vol. 23, no. 2, pp. 141-160, 1999.

[10] Z. F. Zhou, "Inverse analysis of parameters for groundwater movement in fissured double media," Journal of Hydrodynamics, vol. 18, no. 6, pp. 742-747, 2003.

[11] X. He, S. J. Li, and Y. X. Liu, "Identification of hydraulic conductivity of rock mass in dam foundation based on genetic neural network," Chinese Journal of Rock Mechanics and Engineering, vol. 23, no. 5, pp. 751-757, 2004.

[12] X.-S. Liu, C.-B. Zhou, and L.-J. Zhang, "Application of neural network based on simulated annealing Gauss-Newton algorithm to seepage back analysis," Rock and Soil Mechanics, vol. 26, no. 3, pp. 404-406, 2005.

[13] X. Sanchez-Vila, A. Guadagnini, and J. Carrera, "Representative hydraulic conductivities in saturated groundwater flow," Reviews of Geophysics, vol. 44, no. 3, 2006.
[14] J. R. Chai, S. Y. Li, and Y. Q. Wu, "Multi-level fracture network model for coupled seepage and stress fields in rock mass," Communications in Numerical Methods in Engineering, vol. 20, no. 1, pp. 63-74, 2004.

[15] X. H. Deng, "Study on seepage coefficient Identification based on adaptive genetic algorithms," Journal of Northwest $A$ \& $F$ University (Natural Science Edition), vol. 37, no. 10, pp. 221-224, 2009. 


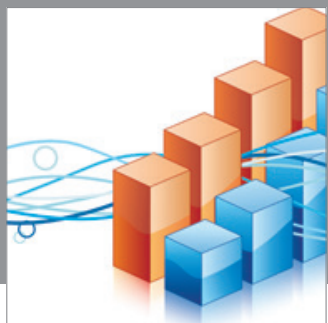

Advances in

Operations Research

mansans

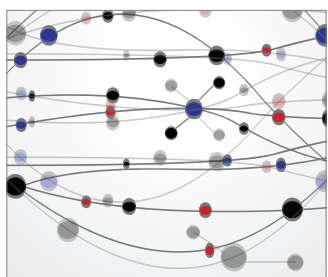

The Scientific World Journal
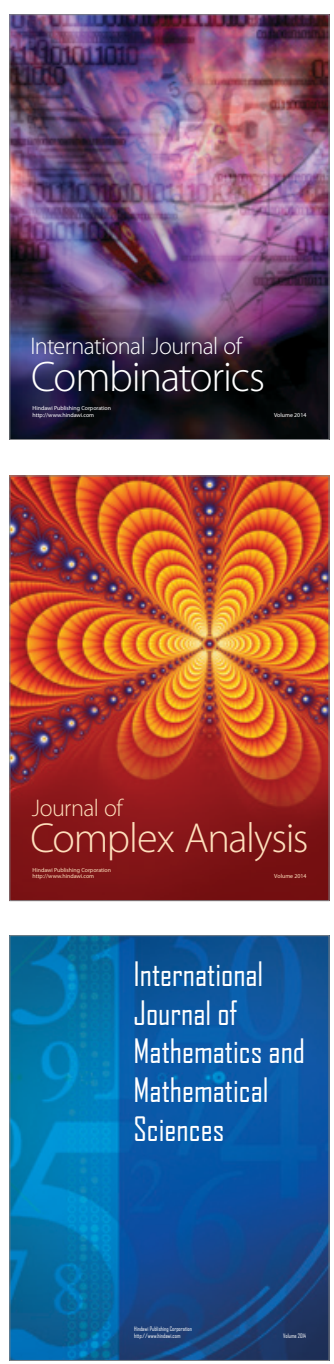
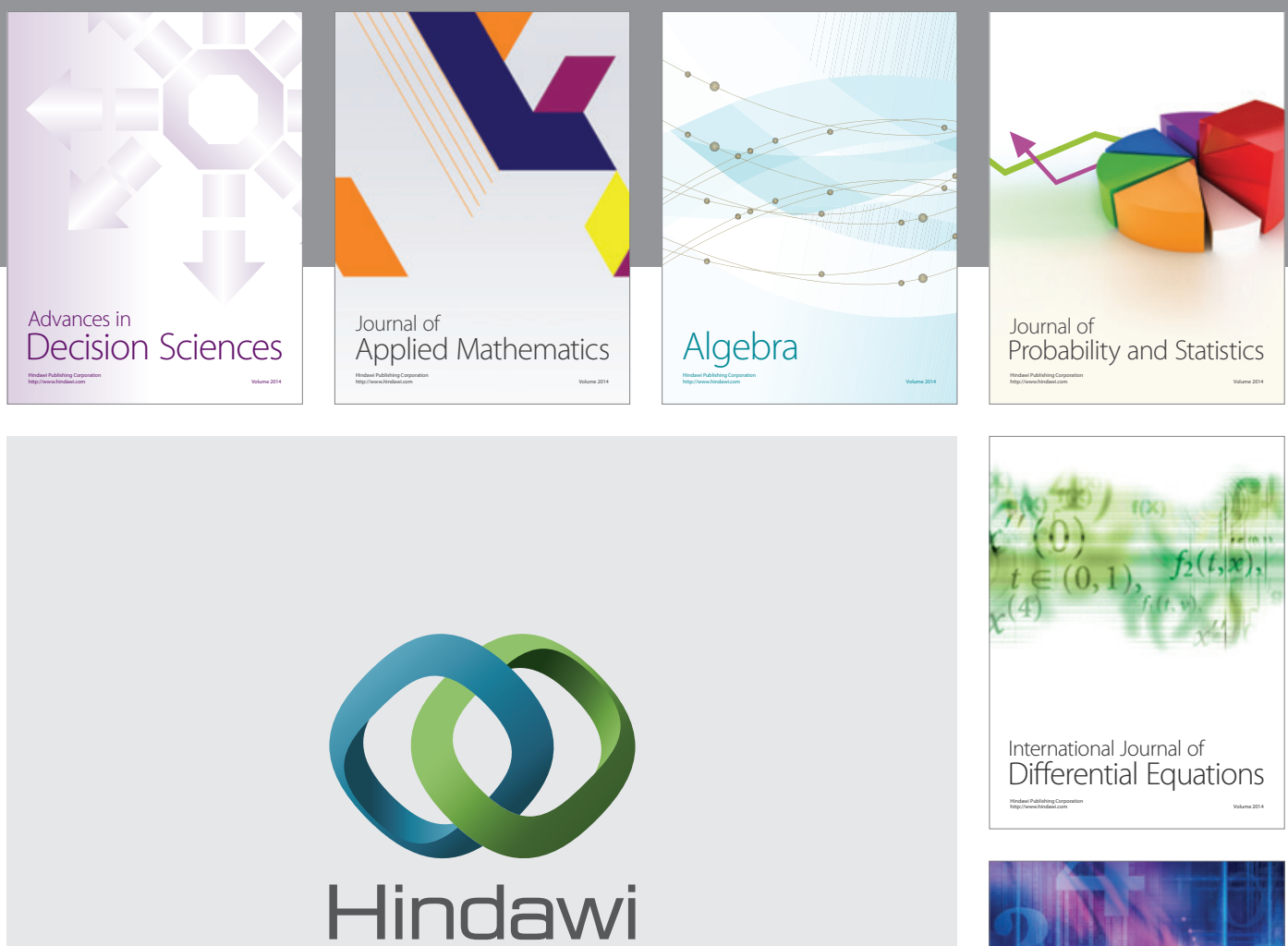

Submit your manuscripts at http://www.hindawi.com
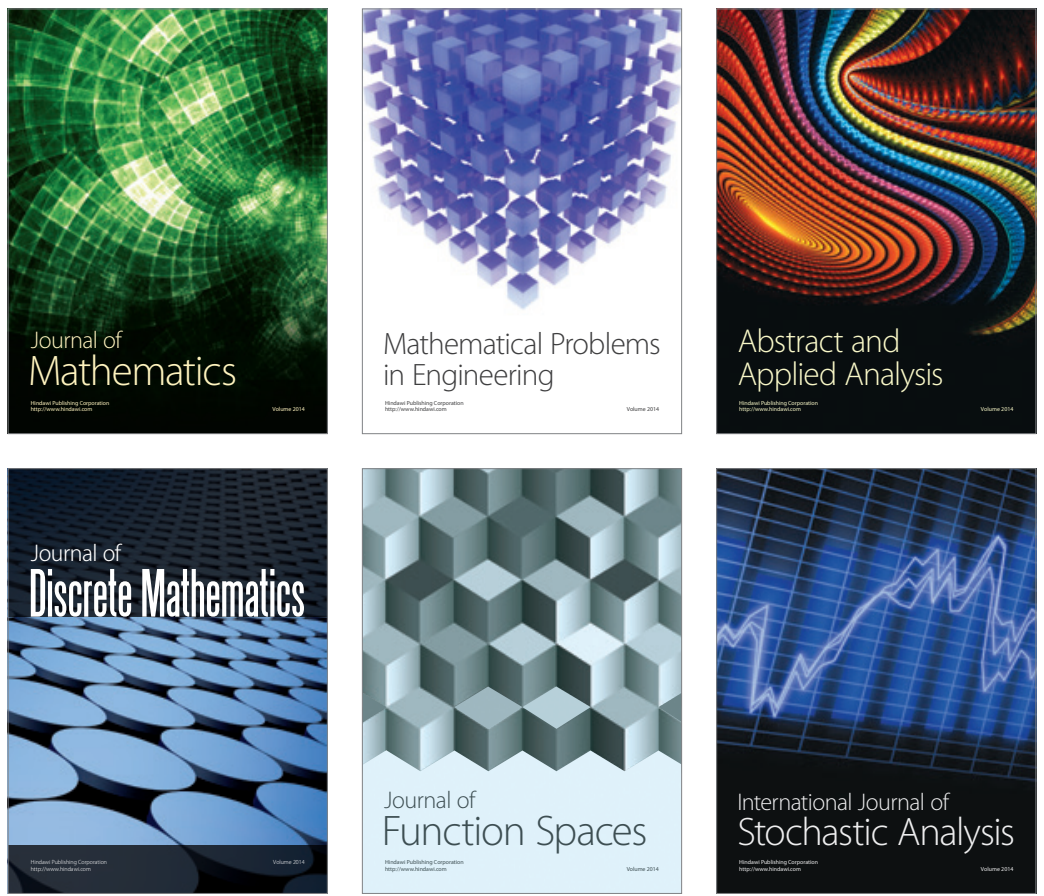

Journal of

Function Spaces

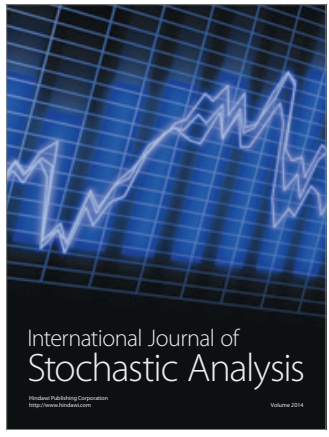

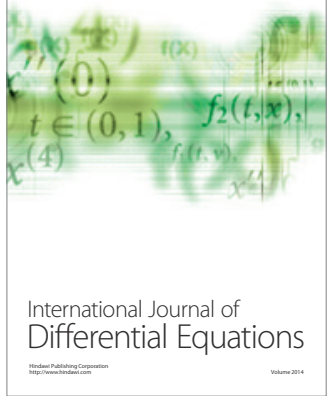
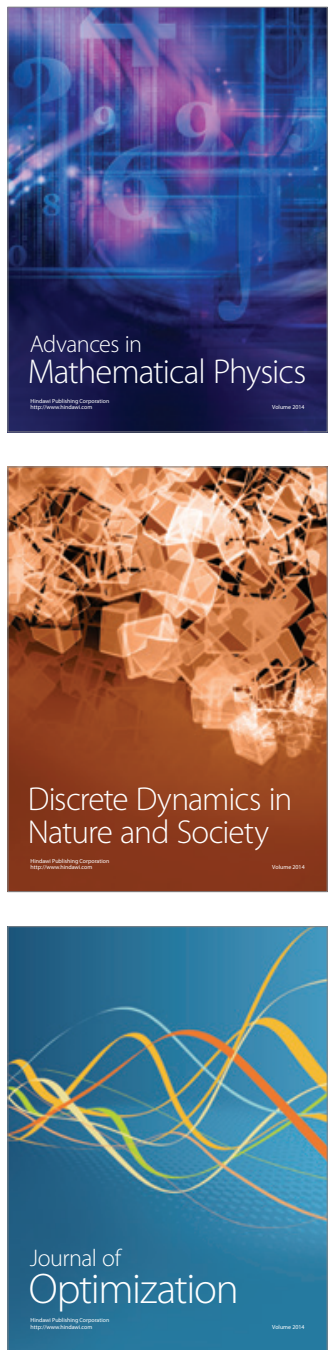